\title{
Online Community : \\ Increase Sales Significantly By Integrating Customer Relationship Management (CRM) With Marketing Communication
}

\author{
( Studi Kasus Partnership KADIN Prov. Jawa Tengah - PT. INDOSAT, Tbk. - PO. NUSANTARA )
}

\begin{abstract}
Online Community looked into by some of party as method to develop again new relation communications medium to powered of organization and individual. Optimism clan assume community of online as excellence of real kompetitif of activity by online representing advantage of network. community of Online represent one of the pioner of marketing of internet which is very promise and create and also grow a community.

According to Hagel \& Armstrong tell that community appearance of online / community appearance of virtual in network of online have created big movement of power which do not be anticipated from supplier \& service to customer. Comprehending the transfer of power \& chosening through community of virtual will obtain customer loyalitas at the same time advantage of impressive economics. Hagel \& Armstrong look into community of online as heart efficacy of commerce by online.

Online community create the condition of where communications \& interaction between important the same customer of with communications among company to customer.
\end{abstract}

Keywords : community online, community of virtual, excellence of kompetitif

\begin{abstract}
Komunitas online dipandang oleh sebagian pihak sebagai metode untuk membangun kembali hubungan sarana komunikasi baru untuk memberdayakan individu dan organisasi. Kaum optimis menganggap komunitas online sebagai keunggulan kompetitif yang nyata dari kegiatan secara online yang merupakan keuntungan dari jaringan. Komunitas online merupakan salah satu pioner dari pemasaran internet yang sangat menjanjikan dan menciptakan serta menumbuhkan suatu komunitas.

Menurut Hagel \& Armstrong mengemukakan bahwa munculnya komunitas online / munculnya komunitas virtual dalam jaringan online telah menciptakan pergerakan besar kekuasaan yang tidak terduga dari penyedia barang $\&$ jasa ke pelanggan. Penyedia yang memahami transfer kekuasaan \& memilih mengkapitalisasikan melalui komunitas virtual akan memperoleh loyalitas pelanggan sekaligus keuntungan ekonomi yang mengesankan. Hagel \& Armstrong memandang komunitas online sebagai jantung keberhasilan perdagangan secara online.

Komunitas online menciptakan kondisi dimana komunikasi \& interaksi antar pelanggan sama pentingnya dengan komunikasi antara perusahaan ke pelanggan
\end{abstract}

Kata kunci : online community, komunitas virtual, keunggulan kompetitif

\section{Pendahuluan}

Sehubungan dengan semakin berkembangnya dunia pemasaran yang menimbulkan semakin tingginya tingkat persaingan antara perusahaan-perusahaan di Indonesia, maka perusahaan-perusahaan tersebut semakin berusaha untuk memperkuat strategi pemasarannya. Strategi pemasaran yang paling efektif digunakan pada saat ini adalah Customer Relationship Management (CRM) dan Marketing Communication yang terintegrasi. 
Definisi dari CRM (Customer Relationship Management) adalah proses dari beberapa tahapan yang terdiri dari Indentifikasi, akuisisi, retensi dan pengembangan customer yang memberikan kontribusi yang besar kepada perusahaan dengan cara memfokuskan strateginya yaitu dengan cara menjaga hubungan dengan customer secara efektif dan efisien sehingga hubungan tersebut menjadi hubungan seumur hidup ("lifetime") yang menguntungkan.

CRM sendiri bukanlah sebuah konsep, melainkan sebuah perubahan paradigma untuk perusahaan-perusahan - dimana CRM itu adalah pola hidup yang bertujuan untuk mengajak customernya menjadi partner dalam perusahaan tersebut dan berkembang untuk mendapatkan keuntungan bersama.

Integrated Marketing Communication ( IMC ) menurut definisi The American Association of Advertising Agencies adalah “ Konsep perencanaan komunikasi pemasaran yang memberikan nilai tambah pada strategi komunikasi yang melibatkan kegiatan sales promotion, periklanan, public relations, direct response yang dipadukan untuk menghasilkan dampak komunikasi yang berarti “.

Komunitas online menggabungkan empat karakteristik yang penting :

Peralatan komunikasi internet

Peralatan yang mengatur keanggotaan komunitas

Kolaborasi produksi materi oleh anggota

Penggunaan yang berulang oleh anggota

Sarana Komunitas Online :

\begin{tabular}{|l|l|}
\hline Rantai Komunikasi & Isi Pokok \\
\hline Daftar surat elektronis & Usenet \\
\hline Net pagers & Bulletin boards \\
\hline Groupware & Chat rooms \\
\hline Permainan \& simulasi & Dunia virtual situs web \\
\hline
\end{tabular}

Menurut sebuat artikel Rayna Skolnik tentang Integrated Marketing yang dimuat oleh

Sales Marketing Network, terdapat empat isu kritikal dalam menerapkan IMC, yakni :

1. Pelanggan makin banyak pilihan dan tuntutannya semakin tinggi. Mereka mempunyai banyak akses ke berbagai produk, memiliki banyak sumber informasi, dan channel untuk membeli,

2. Pasar berubah dari pendekatan " inside-out " marketing menjadi " outside-in " planning sebagai basis CRM dalam mengetahui kebutuhan pelanggan. 
3. Para praktis pemasaran harus mengubah mind-set dari "inilah produk/jasa yang akan saya jual, bagaimana memasarkannya" menjadi 'inilah yang diinginkan konsumen, bagaimana saya menunjukkannya".

4. Perusahaan harus menyadari bahwa pesan yang terpadu harus dihasilkan oleh perusahaan yang terpadu. Jadi persoalannya adalah bagaimana mengkomunikasikannya kepada pelanggan dan konsumen potensial.

\section{Permasalahan}

Permasalahan UKM Berkutat soal Pemasaran

Kelemahan pengembangan usaha mikro, kecil, dan menengah (UMKM) selama ini masih terkendala pada strategi pemasaran, dan perluasan pasar. Karenanya, Kadin Jateng berupaya untuk meningkatkan kualitas pengelolaan UMKM melalui solusi teknologi komputer dalam bisnisnya.

Solichedi, Ketua Kadin Jateng, mengatakan potensi yang dimiliki UMKM belum digarap dengan manajemen modern. Tidak berlebihan bila Kadin terus menyuarakan program pengembangan sektor UMKM.

\section{Pembahasan}

Munculnya permasalahan tersebut, maka KADIN Prov. Jawa Tengah berupaya menggandeng Pihak Pelayanan Jasa Telekomunikasi sebagai penyelenggara jaringan serta penyedia layanan E-Commerce dan pemasaran produk UMKM, yang dalam hal ini diselenggarakan oleh PT. Indosat, Tbk. Program pengembangan layanan operator telekomunikasi seluler terus bergerak. Begitu pun dengan Indosat Regional Jateng-DIY yang meluncurkan berbagai program yang menopang ekonomi daerah. Menyajikan layanan-layanan yang menyesuaikan potensi lokal masing-masing daerah bagi Indosat merupakan peluang bisnis. Salah satu produk yang sedang digarap sebagai bentuk Kemitraan KADIN Prov. Jawa Tengah dengan PT. Indosat, Tbk. adalah layanan ECommerce yang dapat diakses melalui http://www.kadinjateng.com/ infoukm . Selain itu, sektor yang juga dibidik adalah layanan informasi usaha mikro, kecil, dan menengah (UMKM) via VAS SMS Interaktif, Pooling dan Broadcast yang dikelola KADIN secara mandiri untuk kelancaran komunikasi KADIN \& UKM sehingga informasi lebih cepat dan efisien. 


\section{PO. Nusantara}

"Peluncuran bus ber-hot spot ini merupakan salah satu strategi kami meraih pelanggan, khususnya dalam menyambut Visit Indonesia Year 2008," kata Handojo Budianto, pemilik PO Nusantara di kantornya di Kudus akhir pekan lalu. Menurutnya, untuk penyediaan internet, Nusantara bekerja sama dengan Indosat yang menyediakan akses internet berteknologi 3,5 G. Selain itu bus juga dilengkapi peranti global positioning system (GPS). "Jadi kalau penumpang ingin memantau rute perjalanan, tinggal melihat ke layar GPS," tambahnya. Namun, jelas Handojo, sebagai pendukung utama menghadirkan kenyamanan dan teknologi canggih bagi penumpang, Nusantara memilih bus Volvo B12M. Ini jenis terbaru produksi Volvo, yang memang khusus untuk bus pariwisata. Dengan mesin 12.000 cc yang diletakkan di tengah, sehingga getarannya halus. "Bus Volvo tipe ini satu-satunya di Indonesia, dan baru kami yang memakainya," katanya. Hanya memang ada kendala dengan bus ini, yakni tidak bisa disewa ke luar Pulau Jawa. Bodi bus yang terlalu ceper membuat mesin bisa menyeruduk bagian tertentu dari feri penyeberangan. "Jadi bus ini baru bisa dibawa ke objek-objek wisata di Pulau Jawa saja," katanya. Rute ke luar Jawa dan tentu juga objek di Jawa, masih bisa dilayani bus wisata Nusantara lain, yang selama bulan Februari ini tarif sewa didiskon 20 persen. Untuk cyberbus ini dibidik pasar khusus, yakni instansi, perusahaan dan tentu saja orang-orang kaya, yang ingin menikmati layanan khusus selama bepergian. Mereka bisa mengadakan rapat, pesta ulang tahun, atau bahkan yang ingin honeymoon sepanjang perjalanan ke objek wisata juga bisa.

\section{Hasil Pembahasan}

Kelanjutan dari kemitraan tersebut berupa kegiatan berkala seperti Seminar / Edukasi / Sharing Knowledge antar pihak untuk kepentingan Partnership.

\section{Kesimpulan}

Tanpa integrasi dan sinergi antara CRM dan Marketing Communication, hasil yang dicapai oleh brand menjadi tidak optimal. Seperti yang diutarakan di atas, Customer Relationship Management (CRM) dan Integrated Marketing Communication memang bukan barang baru. Tapi persoalannya bagaimana CRM dan IMC dapat membuat perusahaan dan Brand Anda lebih bagus daripada pesaing dan bagaimana memenangkan hati dan pikiran pelanggan Anda.

\section{Daftar Pustaka}

1. http://www.suaramerdeka.com

2. http://www.indosat.com

3. http://www.kadinjateng.com 